\title{
O PROBLEMA DO FLUXO DA CONSCIÊNCIA
}

\section{JEISON ANDRES SUAREZ ASTAIZA ${ }^{1}$}

RESUMO: Os conteúdos da consciência estão em um fluxo perpétuo, mas em que consiste esse fluxo e por que representa um problema? O texto a seguir procura responder a essa pergunta. Na primeira parte, apresentamos a tese geral do naturalismo para caracterizar dois elementos básicos de uma experiência. Na segunda, discutimos a definição que Dewey faz sobre a noção de experiência, em relação aos conceitos de "cumprimento" e "intenção consciente". Em seguida, complementamos com a discussão de duas características com as quais James explica a maneira pela qual o pensamento ocorre, a saber: que o pensamento está sempre mudando e, além disso, é sensivelmente contínuo. Na última parte, apresentamos os conceitos fenomenológicos de antecipação e retenção para mostrar como Husserl tenta explicar, à sua maneira, o problema do fluxo da consciência.

PALAVRAS-CHAVE: Tempo, experiência, fluxo, consciência, pensamento

ABSTRACT: The contents of consciousness are in a constant flux. What does this flow consist of? We will answer this question from the perspective of Dewey, James and Husserl. The problem of the flow of consciousness is exposed: first, from the concepts of fulfillment and conscious intent in Dewey, second, from the idea that thought is always changing and is sensibly continuous in James, and, third, including as moments of the flow of consciousness the structure of anticipation and retention.

KEYWORDS: Time, experience, flux, consciousness, thought

\section{A tese geral do naturalismo}

O naturalismo implica para nós, antes de tudo, uma atitude, a mais óbvia, adotada em resposta à exigência de responder à questão gnoseológica fundamental de como é possível conhecer ou, em um sentido mais específico, como o pensamento acessa e determina o ser. Esse problema básico da filosofia aparece com Parmênides, com a identidade ser-pensar. ${ }^{2}$ Desde então, a tradição filosófica supôs tal identidade como o princípio imóvel para a teoria do conhecimento, ontologia e metafísica. De tal suposição, o pensamento moderno poderia explicar o princípio mais fundamental do conhecimento natural: há conhecimento, consciência, do ser real. A questão capital buscada pela filosofia moderna tem sido a elucidação da verdadeira relação entre ser e conhecer; ${ }^{3}$ a investigação da correlação adequada entre ato,

\footnotetext{
${ }^{1}$ Doutorando em filosofia pela Universidade Federal do Ceará (UFC). E-mail: andressuareza88@ gmail.com.

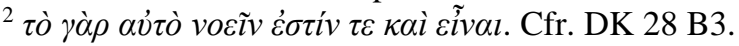

${ }^{3}$ Falo em geral de "conhecer" como um ato ou uma função do pensar.
} 
significação e objeto, ou seja, a realização da possibilidade do conhecimento e a elucidação de sua essência.

Se o conhecimento é o resultado da concordância ou adequação do pensamento com o ser, então como é possível adotar uma atitude "natural" para explicar a possibilidade e a realização do conhecimento? Para responder a essa pergunta, descrevemos uma situação objetiva concreta da vida cotidiana, com a qual esperamos caracterizar o que chamamos de tese geral do naturalismo. Vamos começar com um fato óbvio: que agora me encontro como uma consciência que percebe o mundo. Estou sentado nesta cadeira, em frente à minha mesa, percebendo, prestando atenção aos objetos que estão ali e que aparecem: vejo este livro que está na mesa, percebo a cor branca de suas folhas, sua figura retangular, sua posição levemente inclinada, enquanto sinto a suavidade do papel na minha mão; ouço o som fraco das notas musicais enquanto tenho uma experiência do livro ou mesmo quando sinto a suavidade da cadeira. Tudo isso está acontecendo, e eu estou ciente disso. Apontemos o seguinte: o descrito é uma percepção sensível, simples e particular. Como tal, como intuição, há muitos elementos em jogo que a tornam possível e que constituem níveis diferentes: um subjetivo e outro objetivo, o perceber como um ato de consciência e o livro como objeto de minha percepção. Contudo, ao tentarmos caracterizar a tese geral do naturalismo, devemos dizer que existem, por um lado, órgãos sensíveis e dados de sensações como elementos que constituem um primeiro nível de percepção e, por outro, a unidade objetiva oferecida através dos dados de sensação. No segundo nível de percepção é como elemento fundamental a consciência, melhor, estar ciente das sensações, isto é, o fato de que se possa ter e experimentar sensações de modo que seja capaz de "ver" cores, "ouvir" sons, "sentir" suavidade. Os principais elementos de um terceiro nível são os julgamentos que acompanham a percepção sensorial. Todos esses elementos, e outros que não são mencionados, estão em jogo em uma percepção sensível como a que acabamos de descrever. $^{4}$

Bem, ao descrever uma experiência particular posso afirmar, com certeza, que essa percepção tornou possível o conhecimento de alguns objetos que me cercam e, em certo sentido, de aspectos objetivos do mundo; e que obtive esse conhecimento simplesmente atendendo ao que é oferecido em mera observação. Na descrição do ato particular, sabe-se que o sujeito conhece o objeto. No exemplo anterior: eu, como sujeito que conhece, conheci por experiência o livro, as folhas do livro, a escrivaninha, de uma maneira tão claramente natural que não há

\footnotetext{
${ }^{4}$ A ideia de estabelecer uma gradação por níveis para toda percepção sensível é feita por Descartes para problematizar a certeza dos sentidos. Aqui estamos simplesmente pegando seu sentido mais geral. Cfr. (Descartes, 2008, p. 294-295).
} 
dúvida sobre isso; eu, de alguma forma, apreendi as características do objeto em minha representação total do "livro com a cor branca de suas folhas estendidas em uma certa posição sobre a mesa". Na minha representação, as próprias características que parecem pertencer a esses objetos conhecidos (cor, extensão, posição) estão contidas. Para ser mais exato: ao descrever o anterior ato de conhecimento fica claro para mim e para qualquer outro que percebi objetos - mesa, livro com folhas, cadeira - como coisas que são em si mesmas. É o próprio livro, "em pessoa", que agora está na representação da minha percepção, é sua cor, forma e posição que eu percebi como tal. Aparentemente nada mais evidente que o anteriormente descrito, porque como duvidar que no ato perceptivo, na estrutura da vivência como ato psíquico, há um correlato externo que se dá em presença pessoal como meu objeto? É óbvio supor que existe naturalmente um conhecimento, que, de fato, tenho diante de mim "este livro". Com base nesse fato, posso afirmar que existe realmente para mim o objeto que percebo e que é dado na percepção com suas propriedades particulares.

Agora, a partir da descrição deste fato óbvio, podemos aprofundar em relação à caracterização dos elementos de uma experiência em geral. Levando em conta o exemplo anterior, devemos adicionar dois momentos básicos que compõem qualquer experiência. Primeiro, uma experiência é sempre uma confirmação. Há ou cumprimento ou decepção do sempre novo que traz uma experiência; esta novidade irrompe em minha vida e ao fazê-lo anula ou confirma algo do que estava sendo esperado como uma antecipação. Essa confirmação é uma repetição, em princípio. Por exemplo, agora estou sentado novamente no mesmo espaço de ontem, na mesma cadeira e na mesma mesa; isso não representa nenhuma surpresa para mim, essa experiência não é completamente nova, pelo contrário, encontro-a familiar, não estranha nem nova porque estou habituado. Portanto, uma experiência nunca é totalmente nova e não é que tudo seja exatamente uma surpresa nela, mais bem parece que em cada momento da minha vida, em cada instante do tempo de uma experiência, "algo" volta uma e outra vez, como se os objetos e o mundo se re-confirmassem em sua infinita subsistência: o livro ainda está ali sobre a mesa, a cadeira continua se comportando como uma cadeira, a mesa continua sem perder suas propriedades etc. Sem este retorno não poderia falar-se propriamente de experiência.

Esse retorno ou de-volver-se é o plus da novidade que inclui toda a experiência, e este é o segundo momento que caracterizamos nela. Há também em uma experiência, e esse é talvez o fator mais fundamental, um excesso, um plus, uma novidade. A novidade que irrompe pode cumprir uma expectativa ou decepcionar uma intenção. Assim, em uma experiência, há sempre conformidade, decepção e um fator de novidade. A partir daqui, podemos derivar uma tese 
ontológica muito básica que nos permitirá entender um pouco melhor o caráter de continuidade da experiência e do pensamento. Se numa experiência há sempre cumprimento, decepção e um fator de novidade, então cada coisa e cada fenômeno que se apresenta à experiência é também em certo sentido "novo", da mesma forma que o horizonte geral onde aparecem, isto é, o mundo. Mas o mundo, como os fenômenos, não é 'totalmente' novo, ao contrário, parece ser sempre o mesmo. Assim, cada coisa, cada fenômeno que aparece no horizonte do mundo, dentro do mundo, confirma-se, corrobora-se, aumenta seu sentido, decepciona-se ou frustra-se. Não há momento em que a coisa e o fenômeno não sejam parcialmente novos e velhos ao mesmo tempo, até o mais conhecido e o mais esperado sempre apresenta um fator de novidade, porém esse fator de novidade perde a intensidade de sua irrupção e fica sedimentado no horizonte do mundo como o já realizado.

A tese geral do naturalismo, levando em consideração o exemplo anterior, designa que o sujeito tem consciência perceptiva dos objetos e do mundo como uma realidade que ostenta o caráter de se apresentar como o que realmente está "ali diante"; é por isso que constitui uma evidência em que um julgamento predicativo sobre o ser pode ser fundamentado. Assim, a percepção sensível é sempre mediada por uma atividade específica do pensar ${ }^{5}$ através da qual naturalmente pegamos os objetos como eles nos são apresentados, afirmando-os e colocandoos como existentes no ato de perceber. Nesta "atitude natural" o sujeito atribui um caráter objetivo ao mundo ao qual nossos julgamentos se referem. Os objetos deste mundo são, de fato, e é isso que permite empiricamente seu conhecimento. Assim, a tese geral do naturalismo é uma afirmação constante do conhecimento natural e uma fixação na experiência como ponto de partida para tudo. Naturalmente sempre assumimos a totalidade do ser do mundo e seus objetos porque eles constituem os fatos com os quais e sobre os quais a intuição sensível opera. A intuição sensível é o fundamento dessa atitude. Conhecemos as coisas naturalmente, de fato, e isso não representa problema nenhum.

\section{Cumprimento e intenção consciente na experiência}

$\mathrm{Na}$ seção anterior, caracterizamos a tese geral do naturalismo. Com isso, queríamos descrever a maneira geral pela qual o homem da vida cotidiana obtém conhecimento do mundo

\footnotetext{
${ }^{5}$ Devemos ter em conta que, para James, não existe elemento mediador para o conhecimento de objetos como a intencionalidade da fenomenologia. O próprio pensamento constitui o fato fundamental a partir do qual toda psicologia deve começar. Entretanto, não basta afirmar o pensamento como um fato, mas também deixar claro que "O primeiro fato para nós, portanto, como psicólogos, é que o pensamento, de algum modo, continua (James, 1952, p. 146 [49]). A seguir, citaremos entre parêntesis oblíquos, indicando o ano e o número da página, os textos na sua versão inglesa. Entre parêntesis retos citamos o número da página na correspondente edição em português.
} 
através da experiência. Se tivermos em conta o exemplo da percepção do "livro sobre a mesa", é evidente, para qualquer homem em geral que na percepção, no conhecimento propriamente como ato, existem elementos contidos que pertencem essencialmente à estrutura do próprio objeto. No exemplo, isso significa dizer que percebi a cor branca das folhas, a forma, a posição e o negrume do livro etc. E estes elementos não são outra coisa senão conteúdos primários, como partes ou determinações que constituem associativamente a totalidade do objeto. Esta é a razão pela qual o conhecimento é considerado um fato. Não há dúvida, de fato, que em qualquer percepção sensível são conhecidos objetos que podem ser coisas, seres vivos ou mesmo seres humanos. O que se entende - e por esse motivo é dado de fato - é que eu, o sujeito que conhece, atuo e me relaciono em uma espécie de contínua interação bi-condicional com o objeto de meu conhecimento. Essa interação acontece, portanto, naturalmente e é a base fundamental com a qual é caracterizada a experiência a partir da tese geral do naturalismo. Mas, qual é o problema com esta tese, e por que ela deriva em uma má compreensão do problema do fluxo da consciência?

Retomemos o nosso exemplo para aprofundar cada vez mais os assuntos que nos propusemos. Então: na minha frente eu tenho esse livro que está sobre a mesa, estou tendo uma experiência dele, posso parar na sua forma, na sua cor, em qualquer detalhe, sei que é um "livro", está ali, permanecendo idêntico com todas as suas propriedades. Se afasto o livro da vista, ainda tenho sua imagem, posso representá-lo; em imaginação ou fantasia, consigo lembrar suas páginas, "ver" sua cor novamente. No entanto, trata-se do mesmo livro? Sem dúvida não, por quê? Porque minha experiência do "livro sobre a mesa" é temporária e nela há continuidade e sucessão, mas também "cumprimento":6 "temos uma experiência quando o material experienciado segue seu curso até seu cumprimento" (Dewey, 1987, p. 42 [247]). Uma percepção, e mais especificamente uma experiência, em sentido geral, sempre ocorre em uma continuidade temporal que cessa quando a intenção consciente interpreta o material sensível e atribui-lhe um sentido, uma significação (Dewey, 1987, p. 42 [247]). Isso significa que, para Dewey, uma experiência de pensamento [experience of thinking], em oposição a uma mera experiência, caracteriza-se por ter sua própria qualidade estética (Dewey, 1987, p. 44 [249]). Em alguns casos uma mera experiência pode ser "uma qualidade emocional satisfatória" que tem o objetivo de integrar e cumprir tudo o que passa através da sensibilidade com "um movimento ordenado e organizado" (Dewey, 1987, p. 45 [249]). Então, toda experiência é

\footnotetext{
${ }^{6}$ Decidimos traduzir a expressão "fulfillment" por "cumprimento" e não por "realização".
} 
composta de um material sensível e de uma qualidade estética que age sobre ela, determinandoa e completando-a, ou seja, realizando a experiência e fazendo dela o que é:

O que é ainda mais importante é que não apenas é essa qualidade um motivo significativo para empreender uma investigação intelectual e para que seja conduzida honestamente, como também nenhuma atividade intelectual será um acontecimento integral (uma experiência), a menos que seja integralizada pela mencionada qualidade. Sem ela, o pensar é inconclusivo. Em suma, o estético não pode ser separado de modo taxativo da experiência intelectual, já que esta deverá apresentar cunho estético a fim de que seja completa (Dewey, 1987, p. 45 [249]).

Toda determinação da experiência sempre vai responder a uma qualidade estética. Através da determinação há cumprimento teórico. Mas no caso do cumprimento prático, os motivos para a ação, os interesses, estão sempre no caminho do cumprimento dos valores e bens como objetivos e fins por efetivar; e não pode-se dizer que haja apenas um fim que controle a atenta seleção desses motivos. A vida prática, então, acontece continuamente em uma espécie de cumprimento onde não há ainda, propriamente falando, experiencia estética até que sobre ela atue uma determinada qualidade integralizando-a. Grande parte de nossa experiência passa despercebida e o foco da atenção acaba sendo só o cumprimento objetivo de um respectivo fim. Dewey é claro ao afirmar que não há um "interesse" que possa controlar a atenta seleção ou rejeição do que deve ser organizado em uma experiência em desenvolvimento. Na experiência, mesmo particular, tudo ocorre, as coisas acontecem como fatos que podem ser constatados, nós nos abandonamos aos motivos da experiência, cedemos a eles precisamente em virtude do relacionamento íntimo que sempre temos com o mundo (Dewey, 1987, p. 47 [250-251]). A normalidade e a lassidão da experiência cessam quando uma qualidade a cumpre e a determina, a preenche e lhe dá significado. Uma experiência é especificamente unidade quando uma qualidade estética age sobre ela. Para Dewey, é claro que uma qualidade estética é o que determina uma experiência e a torna particular. Isso lhe permite distinguir entre uma experiência estética e não estética. O não-estético se refere ao passivo, enquanto o propriamente estético implica atividade da mente. A experiência estética é determinada na unidade de uma forma artística que é a expressão de uma qualidade. Portanto, fica claro que, para Dewey, a experiência deve ser uma unidade dada pela qualidade estética: "nenhuma experiência, de que tipo seja, poderá constituir-se numa unidade, a menos que apresente qualidade estética" (Dewey, 1987, p. 47 [251]).

Então, há qualidade estética, unidade e determinação da experiência quando há cumprimento, fins e metas alcançados. Cada experiência integral é sempre movida para um termo, para um cumprimento que vem dado pela qualidade estética que a intenção consciente atribui sobre ela. Esta clausura ou cumprimento da experiência por ação da intenção é 
denominada por Dewey como stasis. A stasis permite uma suspensão entre passividade, receptividade/atividade e generatividade. Não consiste em uma mera recepção de dados e uma criação ativa a partir desses dados. Não, nada disso, porque no meio há vida, e através da experiência, padecimento e sofrimento; portanto, esta atividade é uma incorporação: " "há em toda experiência um elemento de padecimento, de sofrimento, em sentido amplo. De outra maneira não haveria incorporação vital" (Dewey, 1987, p. 48 [251]).

Assim, como acabamos de destacar, para Dewey qualidade e cumprimento são dois componentes essenciais da experiência. No entanto, gostaria de delimitar um pouco melhor, como sugere o título do capítulo do texto de Dewey que aqui consideramos, o que é propriamente ter uma experiência. Depois veremos com James outro componente fundamental não apenas da experiência, mas também da consciência e do pensamento, isto é, seu caráter de continuidade. O que é ter uma experiência? Qual é a sua estrutura temporária?

Os dois momentos da experiência, indicados na seção anterior, permitem entender como surge a questão da continuidade do pensamento. Se em uma experiência há sempre cumprimento e novidade, há necessariamente nela - assim seja em um instante de tempo - algo concreto, patente e manifestamente dado, e, ao tempo, algo mentado, latente e ausente. Uma experiência, nos termos em que a estamos descrevendo, se compõe, então, de um horizonte de efetividade e um horizonte de possibilidade, um âmbito de patência e um de latência, algo concretamente dado que vai acompanhado sempre do vazio co-dado ou co-mentado.

Mas o que tudo isso significa? Se retomarmos nosso exemplo da percepção de "o livro sobre a mesa", temos que dizer o seguinte: que a percepção do objeto é uma inadequação plena. Isto quer dizer que há sempre algo concreto do objeto devido à qualidade estética e algo que se escapa, que se "evade", por assim dizer, da percepção, mas não da experiência. Todo objeto da experiência sempre se dá através de esboços, é inadequado. Não posso nunca esgotar em minha percepção o objeto, por isso as impressões, afecções, sensações que tenho do objeto são sempre parciais. Apesar de tudo na experiência eu tenho a unidade do objeto, "livro", "mesa", de acordo com o exemplo que aqui destacamos. Como sempre acedo ao objeto a partir de um esboço, esse acesso é em cada caso uma determinação daquele aspecto do objeto percebido mas que me remete a outro aspecto que não é percebido na atualidade do ato. Dessa maneira, um objeto, como um livro, só pode ser totalmente percebido por meio de um esboço e apercebido através de uma multiplicidade de aspectos, matizes e esboços. Um objeto como um livro aparece

\footnotetext{
${ }^{7} \mathrm{O}$ termo usado por Dewey é "taking in", que pode ser entendida como uma "interiorização", mas que preferimos traduzir por "incorporação".
} 
arranjado na dualidade patente-latente, eficaz-ineficaz, potência-ato, por um lado, em um horizonte de plenitude, mediado por um ato e um aspecto e, por outro, um horizonte vazio latente - de referência. Portanto, em cada fase da percepção, em cada momento do tempo, o livro é percebido de acordo com o como inerente a um determinado esboço do objeto que foi determinado, e cumprido graças à qualidade estética. Aqui chegamos novamente aos dois conceitos fundamentais que Dewey expõe: cumprimento e intenção consciente. Quando a qualidade estética determina a experiência, a preenche e a cumpre, a intenção consciente emerge. Isso traduzido para o nosso exemplo significa que uma qualidade determina, em um momento do tempo, um aspecto do objeto, fazendo que uma intenção vazia se cumpra com o material sensível, possibilitando a constituição do objeto "livro", "mesa" etc. No cumprimento tomo consciência da minha própria intenção. É por isso que Dewey relaciona imediatamente a experiência com a própria vida, fica claro quando ele afirma que nós, como seres vivos, estamos sempre em constante interação com o mundo, onde tudo parece ocorrer continuamente.

\section{O fluxo do pensamento, da consciência e da vida subjetiva ${ }^{8}$}

A inadequação do objeto não é um aspecto tido em conta por William James. No entanto, a meu ver, ele entende de uma maneira magistral e simples o problema da continuidade e do fluxo da consciência. Assim como o objeto sempre me é dado através de esboços, mutatis mutandis na introspecção, o fluxo da consciência me é dado em suas "partes substantivas" e suas "partes transitivas" (James, 1952, p. 158-159 [62-63]). Em que consiste o fluir da consciência? A primeira coisa a dizer é que, ao tentar responder a esta pergunta, surge subitamente a questão da identidade. Na seção anterior incluímos um par de conceitos que são fundamentais na problemática da identidade: unidade e multiplicidade.

Retomemos novamente o exemplo da percepção do "livro sobre a mesa". Sem entrar muito em detalhes diremos no momento: aquilo que permite ter certeza e afirmar que se trata de um mesmo objeto, quando percebemos algo em determinado curso de consciência, é a convergência dos aspectos em torno da apresentação de tal objeto. Se todos os aspectos que o objeto me oferece convergem na apresentação do mesmo, se as intenções vazias se cumprirem sem tropeço nem interrupção, em determinado curso de consciência, vai-se formando um sistema de convergência que me permite dizer que esse objeto é o mesmo. Esse sistema de

\footnotetext{
${ }^{8}$ Este título tão longo e redundante obedece a James: "A consciência, portanto, não aparece a si mesma talhada em pedaços. Palavras tais como 'cadeia' ou 'sucessão' não a descrevem adequadamente como ela se apresenta na primeira instância. A consciência não é algo juntado; ela flui. Um 'rio' ou um 'fluxo' são as metáforas pelas quais ela é mais naturalmente descrita. Ao falar dela, daqui por diante, chamemo-la o fluxo do pensamento, da consciência ou da vida subjetiva" (James, 1952, p. 155 [60]).
} 
convergência deve cumprir-se tanto para o objeto percebido como para os "estados" da consciência. Este é, portanto, o primeiro ponto de partida de James: a consciência é composta de diferentes estados (James, 1952, p. 150 [53]). A consciência, a mente, para utilizar o mesmo conceito de James, é um todo complexo e constitui o objeto de investigação da psicologia. Enquanto complexo é o resultado de variações e combinações dos elementos simples da consciência. As ideias simples, as sensações propriamente falando, constituem, em princípio, os elementos ou os conteúdos da mente. São os fatos elementares que dentro de um fluxo constituem o pensar mesmo. Estes átomos mentais ou ideias têm sido interpretados pelo empirismo clássico como "elementos simples de consciência, que sempre permanecem os mesmos" (James, 1952, p. 150 [53]). Nossa experiência comum nos permite comprovar a permanência e subsistência dos objetos da percepção, enquanto a introspecção nos permite comprovar a identidade das sensações de nossa mente. No entanto, não são as sensações que obtemos do mesmo objeto, por exemplo, sempre as mesmas? James responde negativamente: "não existe nenhuma prova de que a mesma sensação corporal é, jamais, obtida por nós duas vezes. O que é obtido duas vezes é o mesmo OBJETO”. (James, 1952, p. 150 [54]).

Aqui a pergunta é pelo sentido do que "o mesmo" quer dizer. E isto não é senão um aspecto fundamental e constitutivo de toda experiência que James destaca muito bem: toda realidade parece estar constantemente se apresentando de novo mas, ao tempo, conservando algo. Isso lhe permitirá estabelecer duas premissas seguidas de sua respectiva conclusão. As sensações são atos subjetivos e, diz James, o degrau para passar ao reconhecimento da realidade; por isso, são provas de fato. Um mesmo objeto não pode nos dar duas vezes a mesma sensação. E dado que nossas sensações revelam um mesmo mundo com as mesmas qualidades sensíveis e as mesmas coisas sensíveis:

P1: tanto as sensações como nossa capacidade de sentir estão sempre em mudança P2: a cada sensação deve corresponder-lhe uma ação cerebral (James, 1952, p. 151 [55]) C: não há nem podem haver sensações ou ações cerebrais imutáveis (James, 1952, p. 151 [55]).

Não há ideias simples da sensação nem tampouco é possível falar de um mesmo estado da mente. Nunca duas ideias são exatamente as mesmas: "uma 'ideia' ou 'Vorstellung' permanentemente existente, que faz seu aparecimento no palco da consciência em intervalos periódicos, é uma entidade tão mitológica quanto Jack of Spades" (James, 1952, p. 153 [57]). Não são nem podem ser exatamente "as mesmas" simplesmente porque a consciência, o pensamento e a vida subjetiva estão submetidos à continuidade do tempo. A continuidade da 
consciência significa que em toda consciência pessoal a vida mental é sensivelmente contínua. Como é natural, a continuidade só pode estabelecer-se entre os momentos do fluir de cada consciência, não entre as diversas consciências, que são mundos habitualmente separados entre si (James, 1952, p. 154 [58]). Dentro de cada consciência a interrupção da corrente mental pode ser dupla. Por um lado, a interrupção pode consistir num intervalo de tempo em que nada acontece, "intervalos de tempo dos quais a consciência pode ela própria não estar consciente" (James, 1952, p. 154 [58]). Por outro, pode consistir em uma mudança brusca nos intervalos dos processos mentais que produzem uma queda "na inconsciência", por exemplo, "produzida pelo óxido nitroso e outros anestésicos, pela epilepsia e pelo desmaio" (James, 1952, p. 154 [58]). Assim, para que exista continuidade na consciência, é preciso que aqueles intervalos vazios (por exemplo, o sono) não contem para nada na atividade da mente e que toda mudança qualitativa seja gradual. Deve-se ter em conta que não se trata aqui de um problema de metafísica, mas de psicologia, e que devemos estudar tão somente os dados da consciência; estes nos dirão se existem ou não interrupções no curso da atividade da mente. Por isso outra característica que James reconhece é que "dentro de cada consciência pessoal, o pensamento é sensivelmente contínuo" (James, 1952, p. 146 [49]).

Agora bem, que o pensamento seja "sensivelmente contínuo" não significa que na continuidade não haja rupturas, interrupções ou "intervalos-de-tempo [time-gap] durante os quais a consciência desaparece completamente para voltar à existência novamente em um momento posterior [...] rupturas na qualidade ou conteúdo do pensamento, tão abruptas, que o segmento que segue não teria nenhuma conexão com o que vinha anteriormente" (James, 1952, p. 154 [58]). Esta ideia da continuidade da consciência, atravessada por intervalos de tempo, permitirá a James estabelecer duas premissas importantes:

P1: mesmo onde há um intervalo de tempo, a consciência anterior sente-se como se se integrasse com a consciência posterior (James, 1952, p. 154 [58]).

P2: a mudança de um momento para outro na qualidade da consciência nunca é abrupta (James, 1952, p. $154[58])$.

Estas duas premissas reforçam a ideia da continuidade do pensamento, mas nos colocam diante de um problema a resolver, isto é, o problema de justificar a sucessão e a continuidade dos estados da consciência. James é completamente claro ao afirmar que embora a vida mental se caracterize por ser um constante fluir isso não implica que cada momento desse fluir da consciência tenha o mesmo valor. Há nele elementos ou estados substantivos e elementos ou 
estados transitórios (James, 1952, p. 158-159 [62-63]) ${ }^{9}$. Surge aqui a concepção da vida psíquica como um agregado de elementos ou momentos bem definidos. Os estados transitórios são dificilmente acessíveis à observação interna, mas são bem conhecidos por cada um de nós. Estados mentais transitórios são os de antecipação e de lembrança, por exemplo, quando ao ver a "cara" do livro sei que em seu interior haverá páginas e nelas grafemas. Segundo James, grande parte de nossa atividade mental é constituída por estados transitórios, e sem tê-los em conta a atividade mental é incompreensível. Outros casos de estados transitórios ocorrem ao ouvir, por exemplo, a palavra Olhe! Escuta!, onde tomamos uma atitude expectante graças à antecipação; no entanto, em nossa consciência não há imagens e nada se concretizou ainda nela;. Também o ato de lembrar caracteriza muito bem este tipo de estado transitório. Na maior parte das vezes acontece que nos esforçamos para lembrar o nome da canção que tanto nos agrada e ao não poder fazê-lo normalmente respondemos coisas como "a tenho na ponta da língua".

Mas, o que acontece com a consciência nestes intervalos de tempo? Podem estas interrupções ou cortes da continuidade da consciência serem inconscientes? A resposta de James é apenas óbvia: a consciência deve mesmo ser consciente delas como interrupções de uma continuidade, em nenhum caso a consciência pode ser fragmentada porque "ela sente de modo não fragmentado" (James, 1952, p. 154 [59]). Assim, a consciência não pode perceber as interrupções de sua continuidade objetiva como intervalos porque "seria como esperar que o olho perceba um intervalo de silêncio porque não ouve". Mas mesmo nesta intermitência que caracteriza a consciência deve haver unidade e continuidade. A continuidade da consciência refere-se às "partes sendo interiormente ligadas e reunidas porque são partes de um todo comum, a consciência que permanece sensivelmente contínua e única" (James, 1952, p. 155 [59]). Mas o que é este todo comum? Poderíamos concordar com James e dizer que isso em comum, que dá unidade à consciência e ao pensamento, é a vida subjetiva. Mas, também, poderíamos complementar e dizer que há aqui a possibilidade de supor a ideia de um "Eu" operando nos bastidores da consciência e da vida subjetiva. James não é muito claro na posição que sustenta, dado que quando oferece o exemplo de Paulo e Pedro não pode evitar de falar de um "todo comum" (James, 1952, p. 155 [59]). No entanto, não esclarece em que sentido. Inclusive, é tão radical que reconhece a importância do corpo no pensamento, obviamente um

\footnotetext{
${ }^{9}$ James (1952, p. 158 [62]) explica esta distinção a partir da velocidade da mudança dos estados subjetivos que compõem o fluxo do pensamento. São substantivos "Quando a velocidade é lenta, estamos conscientes do nosso objeto de pensamento de una manera comparativamente tranqüila e estável". São subjetivos "Quando é rápida, estamos conscientes de uma passagem, de uma relação, de uma transição a partir dela ou entre ela e alguma outra coisa"
} 
corpo arraigado num eu: "Nossa própria posição, atitude, condição corporal é uma das coisas em que alguma consciência, ainda que desatenta, acompanha invariavelmente o conhecimento de qualquer outra coisa que conhecemos. Pensamos; e à medida que pensamos, sentimos nossos egos corporais como a sede do pensamento" (James, 1952, p. 157 [61]). Em qualquer caso, James supõe por toda parte a identidade do fluxo da consciência. Tratando-se de estados do pensamento deve-se cumprir este pressuposto: "se um novo estado aparece, a inércia do antigo estado ainda estará ali e modificará o resultado de acordo com ela" (James, 1952, p. 157 [62]). No entanto, como é possível que um estado possa conter elementos de outro estado que já não é, que já passou e perdeu toda sua intensidade no fluxo?

\section{O problema do fluxo da consciência}

Husserl responderá ao problema da continuidade e da sucessão incorporando retenção e antecipação na estrutura do tempo. Dessa forma, toda experiência da vida cotidiana é submetida a uma estrutura que consiste em três momentos: impressão, retenção e antecipação:

\footnotetext{
Se pegarmos o presente pleno [...] temos que dizer de maneira semelhante que o presente passa fluindo para o presente, fluindo progressivamente joga adiante sua antecipação e passa para o novo presente por meio de um constante cumprimento [...] aqui o presente pleno se afunda de forma retencional em um "escuro" recém, e o que vem aqui é também escuro (Husserl, 2006, p. 94-95).
}

Dentro da fenomenologia retenções, antecipações e impressões correspondem aos momentos temporais do agora, do passado e do futuro nas vivências, e, por sua vez, aos momentos temporais dos objetos do mundo. Ao efetuar um corte no processo fluente da percepção, encontramos no lado do percebido uma fase presente momentânea ou "agora" com seu horizonte temporal do que recém foi e do que será. Correlativamente, no lado subjetivo, encontramos uma fase de impressão com seus respectivos horizontes de retenção e antecipação. Toda impressão institui um novo ponto temporal no modo agora. Trata-se de um conceito limite que, por um lado, caracteriza na apresentação a abordagem máxima ao que é percebido e, por outro, não pode ser separado de seus horizontes. A impressão agora é a fonte original da qual a consciência gera de si uma série inteira de transformações. Portanto, o percebido não desaparece sem deixar vestígios, mas permanece consciente através de intenções vazias que passam por modificações novas e sucessivas, transformando-se permanentemente em retenções de retenções até desaparecer no final em um vazio indiferenciado. Cada retenção é uma consciência do passado que corresponde a um ponto agora anterior, com sua determinada distância temporal do agora atual, e que converge com novas impressões. Ao mesmo tempo, um horizonte futuro é formado através das antecipações, como intenções vazias orientadas para 
as fases perceptivas que estão por vir. Então, o verdadeiro problema para Husserl é saber: “como se constitui, ao lado dos 'objectos temporais', o proprio tempo, a duração e sucessão dos objetos?” (Husserl, 1969, p. 22). ${ }^{10}$ A explicação do fluxo da consciência requer correlativamente o esclarecimento da constituição dos objetos temporais, em sua duração e sucessão, através dos momentos temporários de retenção, impressão, antecipação. Vamos ver finalmente como Husserl responde a essa pergunta e qual é a sua posição em relação ao problema do fluxo da consciência.

O ponto de partida de Husserl foi ter mostrado que todo objeto "temporal", seja este imanente ou transcendente, se apresenta à consciência em uma série de fases, em sucessão, e através de perspectivas ou esboços. Cada uma das fases é percebida no momento atual como "agora", "tendo sido" e "ainda não sendo": "Há um 'cada vez' [...] alguma coisa começa e cessa, começa e, depois de seu fim, 'cai' no mais longínquo passado" (Ricoeur, 2010, p. 50). Perceber um objeto temporal implica que a cada uma de suas fases lhe corresponda uma fase "agora" da percepção em virtude da qual cada vez pode ser percebida como "agora". Por isto a percepção é entendida como uma sucessão de fases ou momentos: "agora", "tendo sido", "ainda por vir", portanto, resulta “[...] evidente que a percepção de um objeto temporal tenha ela mesma temporalidade, que a percepção da duração pressuponha ela mesma a duração da percepção, e que a percepção de qualquer figura temporal tenha ela mesma sua figura temporal" (Husserl, 1969, p. 22). Se um objeto temporal é dado sempre na sucessão de suas fases, através de "perspectivas ou esboços" [Abschattugen] (Husserl, 1966, p. 3), sua experiência, como um e o mesmo, se cumpre sob ao menos duas condições: i) que a consciência perceptiva não seja limitada exclusivamente à fase do "agora" porque, se esse for o caso em sentido estrito, seria impossível ter "o mesmo objeto" na duração da percepção e, em vez disso, teríamos uma multiplicidade de objetos diferentes; ii) que junto à consciência da fase do "agora" tenha lugar a consciência das fases passadas e futuras do objeto. A consciência que se dirige aos momentos "passados" e os "ainda por vir", assim como a que se dirige para a fase do "agora", pertence à fase atual da consciência. Husserl distingue, então, entre o que acaba de ter lugar e a lembrança de um ato ou evento que ocorreu em um momento relativamente distante do agora atual. Assim, o co-relato intencional das fases do agora, passado e futuro do objeto são a impressão originária, a lembrança primária ou "retenção" e o futuro primário ou "protensão".

\footnotetext{
${ }^{10}$ Esta questão com algumas modificações aparece novamente nas Análises sobre a Sintese Passiva: "como uma consciência de algo particular e como uma consciência de dados explícitos chegam a ser possíveis como consciência de uma multiplicidade e como consciência de uma totalidade? [...] uma multiplicidade sendo continuamente fusionada em uma unidade dentro de uma consciência, implicite, de tal maneira que a consciência não é consciência de uma multiplicidade" (Husserl, 1966, p. 120 ).
} 
O fluxo das vivências da consciência é garantido pela possibilidade de sintetizar, em relação ao objeto percebido, a retenção e a antecipação à impressão, o que significa que toda experiência além de ser presente inclui uma antecipação ao futuro e uma conservação do passado graças a um processo de modificação retencional. Se lembramos o exemplo da percepção do "livro sobre a mesa", na duração e sequências de suas fases, na duração do ato de perceber a mesa, podemos ver o seguinte: a sequência inicia com a impressão originária $A$; em um momento posterior do tempo, $A$ é retido pelo momento de impressão $B$ e $B$ é retido posteriormente pelo momento de impressão $C$. Porém, na medida em que $B$ retém $A, C$ retém $A$ como retenção de retenção. No momento de impressão $D, C$ é retido junto com sua retenção $B$ (retenção de retenção), e ao fazê-lo retém também o que foi retido por $B$ e assim sucessivamente. $O$ processo de modificação retencional, no entanto, não se estende ilimitadamente senão que, na medida em que as retenções se fundem $^{11}$ no passado, padecem de "um enfraquecimento progressivo que acaba na inadvertência" (Husserl, 1969, p. 31). No outro extremo se encontra a impressão originária, que constitui o núcleo de uma "cauda de cometa de retenções" (Husserl, 1969, p. 30). Em um determinado momento o objeto temporal já não tem apoio na percepção, “ele se desprendeu. É realmente passado. E, contudo, ele se encadeia, faz sequência com o presente e sua cauda de cometa" (Ricoeur, 2010, p. 53). Um objeto, segundo o que acabamos de afirmar, pode ser percebido em virtude da estrutura impressão-retençãoprotensão que o caracteriza a cada fase da consciência e do processo de modificação retencional.

Mas, ainda se poderá falar em unidade? Em fluxo uno? Sim, porque a transformação incessante do "agora" em "não mais", e do "ainda não" num "“agora”, "equivale à constituição de um único fluxo, se a palavra 'constituição' mantiver um sentido quando nada é constituído senão o próprio fluxo" (Ricoeur, 2010, p. 122). Ora, para possibilitar a unidade (dos atos, sensações e do fluxo mesmo) a consciência deve realizar duas tarefas: sintetizar o próprio fluxo e tornar o fluxo consciente de si. Mas, como opera a consciência para, ao mesmo tempo, dar unidade e possibilitar a auto-captação do fluxo? Ricoeur aponta como aqui parece haver um paradoxo, pois "o fluxo de consciência constitui sua própria unidade” (Ricoeur, 2010, p. 122). A saída de Ricoeur para resolver esta "aparente" dificuldade é a seguinte: "de um lado, a unidade da coisa que dura se constitui através das fases; de outro o olhar se dirige sobre o

\footnotetext{
${ }^{11}$ Esse processo de modificação retencional tem um limite, isto é, não se estende infinitamente como modificação de modificação senão que se detém: "Antes eu disse que essa corrente de retenção e a constituição do passado se afastam constantemente na escuridão total. Mas parece-me que essa hipótese pode ser descartada. O processo em si termina" (Husserl, 1966, p. 177). No entanto, esse "acabamento" deve ser entendido como "submergir" [Herabsinken] ou "afundamento". Cfr. (Husserl, 1969, p. 28).
} 
fluxo" (Ricoeur, 2010, p. 122). Esta postura é adequada porque "no fluxo uno, único, de consciência, se constitui a unidade temporal imanente [...] e ao mesmo tempo a unidade do próprio fluxo de consciência” (Husserl, 1969, p 80). Isto é, enquanto o objeto transcendente se distingue dos atos através dos quais é constituído e as unidades imanentes são, em certo sentido, diferentes da consciência que faz possível sua experiência, o fluxo absoluto se auto-constitui e é experimentado a partir de si mesmo. Em outras palavras, na consciência absoluta o constituinte e o constituído coincidem. A teoria da dupla intencionalidade vai mostrar esta coincidência.

Cada fase do fluxo está dirigida intencionalmente a alguma fase de um ou vários objetos, mas, ao mesmo tempo, cada fase do fluxo está relacionada intencionalmente com outras fases do mesmo. Se temos em conta a primeira direção da intencionalidade compreendemos que a impressão primária é o "momento" do curso absoluto em virtude do qual cada fase do objeto é experimentada como "agora". Uma primeira forma de retenção conserva a fase do "agora" (Husserl, 1969, p. 81). Quando esta transcorre, a protensão intenciona a fase do objeto ainda por vir. Dessa forma, impressão, retenção, protensão constituem a intencionalidade transversal [Querintentionalität] do curso, isto é, a consciência do tempo no modo "agora, passado e futuro" (Ricoeur, 2010, p. 122). Pois bem, quando a fase "agora" do objeto intencional transcorre, o mesmo acontece com a impressão originária que a havia intencionado. E quando uma nova fase atual da consciência absoluta retém o momento anterior do curso, retém também a fase que havia sido retida por ele. Se produz assim um continuum de retenções que constitui o curso absoluto como uma unidade, cabe dizer, um todo constante "de modos de consciências, de modos do ser decorrido; de aparecer um após o outro ou juntos - simultaneamente - é o que se costuma chamar sucessão e coexistência" (Ricoeur, 2010, p. 122). Aqui já está indicada a segunda direção da intencionalidade, aquela dirigida agora sobre o próprio curso e que Husserl chama longitudinal [Längsintentionalität]. Assim temos que a intencionalidade transversal (QI) se fixa na coisa que dura enquanto a intencionalidade longitudinal (LI) se fixa nas retenções e na série de retenções. O que comprovamos aqui é a implicação mútua entre a síntese temporal e seu conteúdo, pois, se bem é possível distinguir ambos os modos da intencionalidade, é claro que não são separáveis um do outro.

O fluxo temporal da consciência é, assim, uma rede contínua de retenções de retenções e antecipações de antecipações, que podem ser estendidas indefinidamente em direção ao passado e ao futuro. O agora se junta a uma série de passados e futuros que mudam continuamente sua maneira de se unir, mantendo o relacionamento que têm entre si. E sem essa 
modificação contínua dos momentos temporais, o caráter fluente do presente e, portanto, da consciência não seria possível. O fluxo inerente ao presente gera um horizonte temporal: "No presente proto-original que permanece e flui, o curso temporalizado da consciência no modo do horizonte é constituído de maneira fluente" (Husserl 2006, p. 351). O fluxo da consciência, então, é orientado em várias direções associadas aos horizontes temporais: o presente fluente é presente do pasar fluindo [Verströmen], do afastar-se fluindo [Abströmen] e do afluir [Zuströmen]" (Husserl, 2006, p. 12).

\section{REFERÊNCIAS BIBLIOGRÁFICAS}

DESCARTES. Meditations on First Philosophy. The philosophical writings of Descartes, Vol. II. New York: Cambridge University Press, 2008.

DEWEY. Having an Experience. Art as experience. Carbondale: Southern Illinois University Press, 1987, pp. 42-63.

Tendo uma experiência. A arte como experiência. São Paulo: Abril Cultural, Série Os pensadores, 1974, pp. 254-263.

HUSSERL. Analysen zur passiven Synthesis. Aus Vorlesungs und Forschungsmanuskripten, 1918-1926. Den Haag: Martinus Nijhoff, 1966.

_ Vorlesungen zur Phänomenologie des inneren Zeitbewusstseins (1893-1917). Den Haag: Martinus Nijhoff, 1969.

— Die 'Bernauer Manuskripte' über das Zeitbewußtsein (1917/18). Dordrecht: Springer, 2001.

Späte Texte über Zeitkonstitution. Die C-Manuskripte. Dordrecht: Springer, 2006.

JAMES. The Stream of Thought. Principles of psychology. Chicago: Encyclopaedia Britannica, 1952, pp. 146-161.

O fluxo do pensamento. Princípios de psicologia. São Paulo: Abril Cultural, Série Os pensadores, 1974, pp. 49-97.

KIRK, RAVEN \& SCHOFIELD. Parménides de Eleia. Os filósofos pré-socráticos. História crítica com selecção de textos. Lisboa: Fundação Colouste Gulbenkian, 2010, pp. 249-273.

RICOEUR. A memória, a história, o esquecimento. São Paulo: UNICAMP, 2010 